\title{
Diagnostic accuracy and comparison of BIPSS in response to lysine vasopressin and hCRH
}

\author{
Kush Dev Singh Jarial' ${ }^{1}$ Anil Bhansali', Vivek Gupta ${ }^{2}$, Paramjeet Singh ${ }^{2}$, Kanchan K Mukherjee ${ }^{3}$, \\ Akhilesh Sharma ${ }^{4}$, Rakesh K Vashishtha ${ }^{5}$, Suja P Sukumar', Naresh Sachdeva' and Rama Walia ${ }^{1}$ \\ 'Department of Endocrinology, Post Graduate Institute of Medical Education and Research, Chandigarh, India \\ ${ }^{2}$ Department of Radio-diagnosis, Post Graduate Institute of Medical Education and Research, Chandigarh, India \\ ${ }^{3}$ Department of Neurosurgery, Post Graduate Institute of Medical Education and Research, Chandigarh, India \\ ${ }^{4}$ Department of Psychiatry, Post Graduate Institute of Medical Education and Research, Chandigarh, India \\ ${ }^{5}$ Department of Histopathology, Post Graduate Institute of Medical Education and Research, Chandigarh, India \\ Correspondence should be addressed to R Walia: ramawalia@rediffmail.com
}

\begin{abstract}
Context: Bilateral inferior petrosal sinus sampling (BIPSS) using hCRH is currently considered the 'gold standard' test for the differential diagnosis of ACTH-dependent Cushing's syndrome (CS). Vasopressin is more potent than CRH to stimulate ACTH secretion as shown in animal studies; however, no comparative data of its use are available during BIPSS.

Objective: To study the diagnostic accuracy and comparison of hCRH and lysine vasopressin (LVP) stimulation during BIPSS.

Patients and methods: 29 patients (27-Cushing's disease, 2-ectopic CS; confirmed on histopathology) underwent BIPSS and were included for the study. Patients were randomized to receive hCRH, $5 \mathrm{U}$ LVP or $10 \mathrm{U}$ LVP during BIPSS for ACTH stimulation. BIPSS and contrast-enhanced magnetic resonance imaging (CEMRI) were compared with intra-operative findings of trans-sphenoidal surgery (TSS) for localization and lateralization of the ACTH source.

Results: BIPSS correctly localized the source of ACTH excess in 29/29 of the patients with accuracy of $26 / 26$ patients, using any of the agent, whereas sensitivity and PPV for lateralization with hCRH, 5 U LVP and $10 \mathrm{U}$ LVP was seen in 10/10, 6/10; 10/10,8/10 and 7/7,6/7 patients respectively. Concordance of BIPSS with TSS was seen in 20/27, CEMRI with BIPSS in 16/24 and CEMRI with TSS in 18/24 of patients for lateralizing the adenoma. Most of the side effects were transient and were comparable in all the three groups.

Conclusion: BIPSS using either hCRH or LVP $(5 \mathrm{U}$ or $10 \mathrm{U})$ confirmed the source of ACTH excess in all the patients, while $10 \mathrm{U}$ LVP correctly lateralized the pituitary adenoma in three fourth of the patients.
\end{abstract}

\author{
Key Words \\ - bilateral inferior petrosal \\ sinus sampling (BIPSS) \\ - hCRH (human \\ corticotrophin releasing \\ hormone) \\ - LVP (lysine vasopressin) \\ - contrast-enhanced \\ magnetic resonance \\ imaging (CEMRI)
}

Endocrine Connections (2018) 7, 425-432

\section{Introduction}

The differential diagnosis of ACTH-dependent Cushing's syndrome (CS) as pituitary or ectopic source of ACTH production is often challenging for the physicians as none of the biochemical tests or imaging modalities have 100\% diagnostic accuracy (1). Cushing's disease (CD) accounts for about $90-95 \%$ of the cases when there is no obvious source of ACTH hypersecretion, and this distinction is essential to decide further therapeutic strategies $(2,3,4$, 5). Sellar imaging fails to detect small adenomas in 50\% of the patients with Cushing's disease and further this

$$
\begin{array}{lr}
\text { http://www.endocrineconnections.org } & \text { ○ } 2018 \text { The authors } \\
\text { https://doi.org/10.1530/EC-18-0046 } & \text { Published by Bioscientifica Ltd }
\end{array}
$$

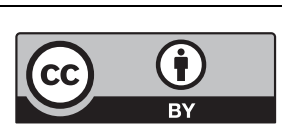


is complicated by the fact that pituitary incidentaloma can be found in 10-30\% of the general population (6). BIPPS demonstrated $100 \%$ sensitivity and specificity in differentiating pituitary from peripheral source of ACTH production in the earlier studies; however, recent studies have shown lower accuracy due to the false-positive (pseudo Cushing's states and on medical treatment) and false-negative results (cyclical CS) (7, 8, 9). Ovine or hCRH and/or desmopressin have been used to stimulate corticotropes during BIPSS to improve the accuracy of the procedure for localizing the source of ACTH hypersecretion and were found to be equipotent in stimulating ACTH production $(10,11,12)$. Animal studies have shown that vasopressin is more potent stimulus for ACTH secretion than CRH. However, human studies have shown that vasopressin is equipotent to hCRH for ACTH release $(13,14,15)$. Desmopressin has higher affinity for V2 receptors present on the kidney as compared to that for $\mathrm{V} 3$ receptors present on pituitary. Further, vasopressin is more potent than desmopressin in ACTH release due to its higher affinity for V3 receptors present on pituitary, and it also increases the CRH release $(16,17)$. Vasopressin was used during BIPSS in a previous study; however, the patients were few (18).

The present study was performed to compare the diagnostic accuracy of human hCRH and lysine vasopressin for stimulating ACTH release during BIPSS in localizing and lateralizing the source of ACTH hypersecretion.

\section{Patients and methods}

\section{Bilateral inferior petrosal sinus sampling (BIPSS)}

The diagnosis of CS was based on clinical symptoms and signs, ACTH-dependent hypercortisolemia, nonsuppressible cortisol dynamics, sellar imaging either normal or showing pituitary microadenoma and adenoma or carcinoid on histopathology following trans-sphenoidal or appropriate surgery. Twenty-nine consecutive patients of CS; twenty-seven patients of Cushing's disease having microadenoma (confirmed on histopathology) and 2 patients of ectopic CS (bronchial carcinoid -1, thymic carcinoid 1) in whom BIPSS was performed were included in the study from April 2013 to November 2015. BIPSS was performed in the neuroradiology unit of the institute. All the patients included were hypercortisolic (raised midnight plasma cortisol, urinary free cortisol and non-suppressible cortisol on ONDST (overnight dexamethasone suppression test) or LDDST (low dose dexamethasone suppression test)) and had raised ACTH. ONDST was performed by

$$
\begin{array}{lr}
\text { http://www.endocrineconnections.org } & \text { (อ) } 2018 \text { The authors } \\
\text { https://doi.org/10.1530/EC-18-0046 } & \text { Published by Bioscientifica Ltd }
\end{array}
$$

orally administering a 1-mg tablet of dexamethasone at 23:00 h, and a blood sample for cortisol was collected at 08:00 h the next day. Plasma cortisol above $50 \mathrm{nmol} / \mathrm{L}$ was taken as non-suppressible. LDDST was performed by orally administering 0.5-mg tablets of dexamethasone at 09:00, 15:00, 21:00 and 03:00 h for 48 h, and blood samples for cortisol were collected at 08:00 h. Plasma cortisol above $50 \mathrm{nmol} / \mathrm{L}$ was taken as non-suppressible. On the day of BIPSS procedure, 08:00 $\mathrm{h}$ plasma cortisol was elevated in all the patients, thus excluding cyclicity. Bilateral inferior petrosal sinuses were catheterized using femoral route under local anesthesia. 5 French catheters were used to reach the bilateral petrosal sinuses. Once catheters were placed in the petrosal sinuses, position was confirmed using fluoroscopic guidance. Catheterization of the bilateral inferior petrosal sinuses was successful in all the patients. Simple random sampling using random number table was done for the selection of agent for stimulation during BIPSS. hCRH (CRH Ferring $100 \mu \mathrm{g}$, Unipharma SA) was used in 10 patients. 10 U LVP was used in 9 patients while $5 \mathrm{U}$ LVP was used in 10 patients to find out the minimum effective dose of LVP for ACTH stimulation. LVP diluted in $10 \mathrm{~mL}$ of normal saline was given intravenously through peripheral catheter over six minutes, whereas $100 \mu \mathrm{g}$ hCRH was given intravenously as a bolus through peripheral catheter after mixing it with the diluent. Blood samples were drawn at basal (-6 min), 0, 2, 3, 5, 10 and $15 \mathrm{~min}$ and were stored in pre-chilled EDTA tubes. The patients were monitored for blood pressure, heart rate, oxygen saturation or any other complaint reported by them. Samples were immediately transported to the endocrinology laboratory of the institute for processing. Standardized cut-off value for inferior petrosal sinus to peripheral venous ACTH of $\geq 2: 1$ for the basal and $\geq 3: 1$ after stimulation were considered to denote the pituitary source of ACTH excess, while inter-sinus ACTH ratio of $\geq 1.4$ :1 was taken for lateralization of ACTH source.

Ethical approval was taken from the Ethics Committee of PGIMER, Chandigarh, India. Informed written consent was obtained from all the patients.

Imaging, trans-sphenoidal surgery and histopathology

Dynamic contrast enhanced magnetic resonance imaging (CEMRI) was done in all the patients with ACTH-dependent CS. Contrast-enhanced computerized tomography (CECT) chest and abdomen were done in patients with ectopic CS. Patients with Cushing's disease underwent TSS, while resection of the respective

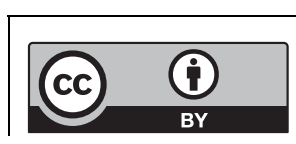

This work is licensed under a Creative Commons Attribution 4.0 International License. 
tumor was performed in patients with ectopic CS. Intraoperative findings regarding tumor location, its tumor epicenter, tumor extension and so forth were recorded by surgeon during TSS and correlated with MRI and BIPSS. Histopathological findings were considered as the 'gold standard' for the diagnosis of CS.

\section{Assay}

Serum cortisol and ACTH were measured by electro-chemiluminescence-immuno-assay

(ECLIA) (ELECSYS-2010, Roche Diagnostics). Inter-and intra- assay CV was $2.3 \%, 6.4 \%$ and $1.4 \%, 2.8 \%$ for ACTH and plasma cortisol, respectively.

\section{Statistical analysis}

SPSS, version 17 has been used for statistical analysis. Descriptive statistics has been used and expressed in the form of frequencies and proportions. Significance value has been considered at $P \leq 0.05$. For calculating the sensitivity and specificity of various diagnostic tests, a gold standard for establishing diagnosis has been considered in the form of intra-operative localization and lateralization of tumour. Sensitivity and positive predictive derived for the various tests in this study by generating a classical $2 \times 2$ contingency cross table. Comparison of predictive values for the two stimulating agents was done using 'N-1' Chi squared test. For calculating the concordance for localizing and lateralizing the ACTH source, simple manual case-by-case comparison was done.

\section{Results}

\section{Comparison and diagnostic accuracy of BIPSS for localizing and lateralizing ACTH source with hCRH or LVP}

At the basal point of time (prior to stimulation), sensitivity and PPV of BIPSS for the localization of ACTH source was seen in $26 / 29$ and $26 / 26$ of patients, respectively. Further, BIPSS was able to localize the source of ACTH in
29/29 patients at 2 and 3 min after stimulation using LVP (either $5 \mathrm{U}$ or $10 \mathrm{U}$ ) and hCRH, respectively.

At basal point of time (prior to stimulation), sensitivity for lateralization of pituitary adenoma during BIPSS was 22/27; and $16 / 22$ of patients had accurate lateralization of the ACTH source. Post-stimulation during BIPSS, 27/27 patients lateralized pituitary adenoma with any of the stimulating agent, while PPV for lateralization of $6 / 10$, 8/10 and 6/7 was observed with hCRH, $5 \mathrm{U}$ LVP and $10 \mathrm{U}$ LVP respectively.

Pituitary lesion $\leq 6 \mathrm{~mm}$ has a higher chance than lesion larger than $6 \mathrm{~mm}$ of being pituitary incidentaloma and being the real cause for hypercortisolism in the patient. The role of BIPSS becomes more important in this scenario. We tried to find out the performance of BIPSS in microadenoma $\leq 6 \mathrm{~mm}$. In patients with pituitary adenoma $\leq 6 \mathrm{~mm}$, BIPSS lateralized adenoma in $16 / 16$ of the patients, while accuracy of lateralization was $3 / 4,5 / 7$ and $4 / 5$ with hCRH, $5 \mathrm{U} \mathrm{LVP}$ and $10 \mathrm{U}$ LVP respectively; which was further substantiated by histopathology. Lateralization with BIPSS correlated with the intraoperative findings during TSS in all the three patients who had normal CEMRI sella.

Maximum stimulated ACTH level of $20,000 \mathrm{pg} / \mathrm{mL}$ was achieved with $5 \mathrm{U}$ LVP, while maximum ACTH level of $3848 \mathrm{pg} / \mathrm{mL}$ was obtained after hCRH stimulation (Table 1). Both the patients of ectopic CS did not achieve the basal and stimulated recommended cut-off of 2:1 and $3: 1$, respectively.

TSS was performed in 27 patients. Patients with ectopic CS underwent surgery confirming bronchial carcinoid and thymic carcinoid in one patient each, respectively. 24 patients had microadenoma on CEMRI, while in three patients MRI was normal. Concordance of BIPSS and CEMRI in lateralizing adenoma was seen in $16 / 24$ of the patients (4/8, 6/9 and 6/7 with hCRH, $5 \mathrm{U}$ LVP and $10 \mathrm{U}$ LVP respectively). Concordance in lateralizing adenoma between BIPSS and TSS was observed in 20/27 of patients (6/10, 7/9 and 7/8) with hCRH, 5 U LVP and 10U LVP, respectively) and concordance of CEMRI with TSS was observed in $18 / 24$ of patients.

Sixteen patients had pituitary adenoma size $\leq 6 \mathrm{~mm}$. In these patients, concordance of BIPSS and CEMRI was

Table 1 Comparison of LVP 10U, LVP 5 U and hCRH.

\begin{tabular}{|c|c|c|c|}
\hline & Max ACTH (pg/mL) & $\begin{array}{c}\text { Max ACTH } \\
\text { ratio }(C: P)\end{array}$ & Max inter-sinus ratio \\
\hline AVP (10U) & 1687 (2 min) & 140.1 (2 min) & $27.5(2 \mathrm{~min})$ \\
\hline AVP (5U) & 20000 (1 min) & 122.8 (2 min) & 57.6 (3 min) \\
\hline $\mathrm{hCRH}$ & 3848 (3 min) & 146.8 (3 min) & 59.3 (3 min) \\
\hline $\begin{array}{l}\text { http://www.e } \\
\text { https://doi.or }\end{array}$ & $\begin{array}{l}\text { Adocrineconnections.org } \\
\text { g/10.1530/EC-18-0046 }\end{array}$ & & $\begin{array}{l}\text { (c) } 2018 \text { The authors } \\
\text { hed by Bioscientifica Ltd }\end{array}$ \\
\hline
\end{tabular}

\begin{tabular}{c}
$\begin{array}{c}\text { Sensitivity of lateralization } \\
\text { post stimulation }\end{array}$ \\
\hline $9 / 9$ \\
$10 / 10$ \\
$10 / 10$
\end{tabular}

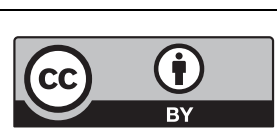

This work is licensed under a Creative Commons Attribution 4.0 International License. 


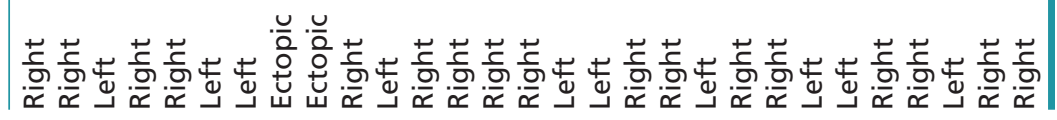

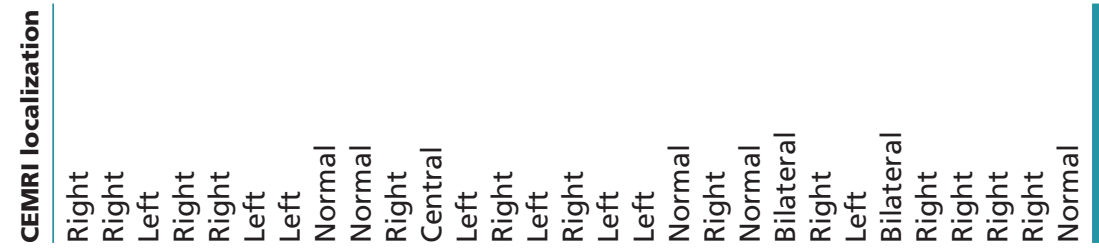



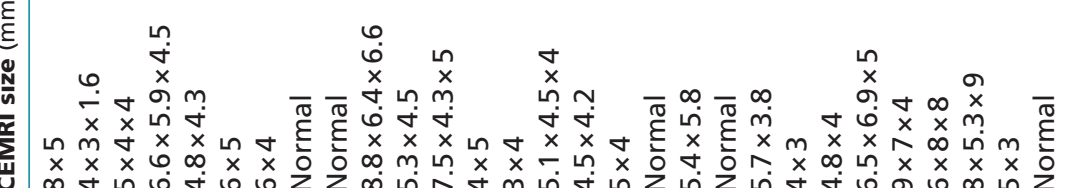
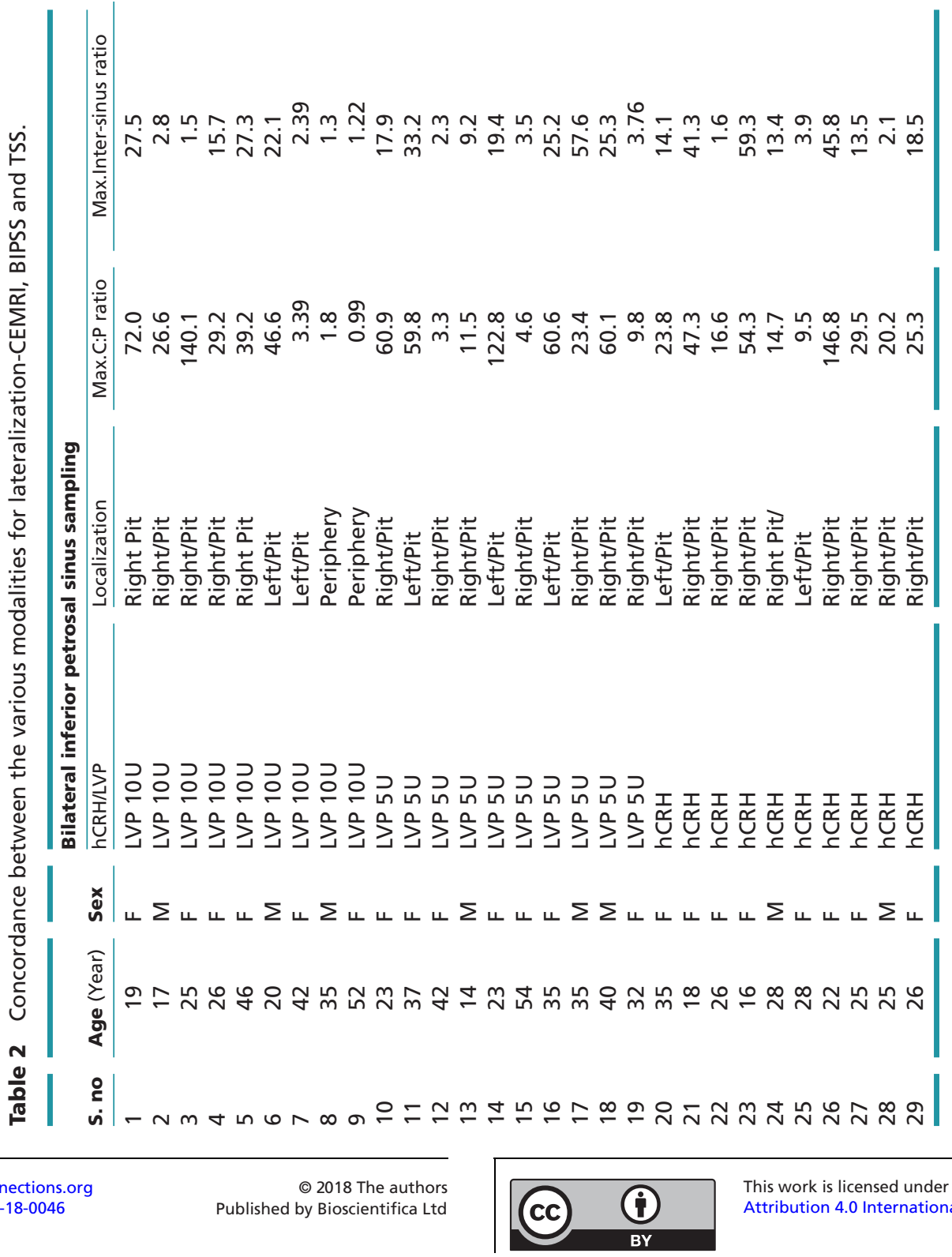
Table 3 Side effects of lysine vasopressin, hCRH and procedure related.

\begin{tabular}{|c|c|c|c|}
\hline Side effects & LVP $10 U(n=9)$ & LVP $5 \mathbf{U}(n=10)$ & hCRH $(n=10)$ \\
\hline Hypertension & 7 & 6 & 2 \\
\hline Hypotension & 0 & 0 & 4 \\
\hline Bradycardia & 2 & 2 & 0 \\
\hline Tachycardia & 0 & 0 & 10 \\
\hline Headache & 3 & 4 & 4 \\
\hline IJV thrombosis & 0 & 0 & 1 \\
\hline Ear ache & 0 & 0 & 1 \\
\hline Fall in $\mathrm{SpO}_{2}$ & 1 & 1 & 0 \\
\hline Nausea & 2 & 2 & 0 \\
\hline Pain abdomen & 1 & 1 & 0 \\
\hline Flushing & 0 & 1 & 2 \\
\hline Total events & 16 & 17 & 23 \\
\hline
\end{tabular}

seen in $12 / 16$ of the patients $(3 / 4,5 / 7$ and $4 / 5$ with hCRH, $5 \mathrm{U}$ LVP and 10U LVP respectively), BIPSS with TSS in $13 / 16$ patients $(3 / 4,5 / 7$ and 5/5 with hCRH, $5 \mathrm{U}$ LVP and 10U LVP respectively), while for CEMRI and TSS concordance was observed in 12/16.

In seven patients in whom CEMRI was discordant with BIPSS, five patients had concordance of CEMRI with intraoperative localization during trans-sphenoidal surgery, suggesting that when CEMRI and BIPSS are discordant, then CEMRI has better correlation for the lateralization of the tumor during TSS. Table 2 shows details of the BIPSS, CEMRI and histopathology findings.

\section{Side effects of drugs used in BIPSS for stimulation and procedure-related complications}

Transient hypertension was the commonest side effect associated with use of LVP, while tachycardia was the commonest side effect associated with the use of hCRH. These side effects were mild and transient in nature abated by themselves without any intervention. One patient in the hCRH group developed internal jugular vein thrombosis after the procedure which resolved after anticoagulation therapy. Table 3 shows the profile of side effects observed during the procedure.

\section{Discussion}

The present study was performed to compare the diagnostic accuracy of lysine vasopressin and hCRH as stimulating agent for the ACTH release during BIPSS to localize and lateralize the source of ACTH in patients with CS. This study showed that both these agents confirmed the source of ACTH excess in all of the patients. BIPSS using 10 units
LVP correctly lateralized the pituitary adenoma in more than three-fourth of the patients, which was higher as compared to hCRH or $5 \mathrm{U}$ LVP, although this was not significant statistically. Side effects of both these agents were mild and transient except internal jugular vein thrombosis on right side post procedure in one patient in hCRH group.

Simultaneous BIPSS helps to differentiate between pituitary and the ectopic tumoral ACTH secretion and can provide clue about the site of pituitary adenoma (lateralization). BIPSS is performed in patients of ACTHdependent CS when there are discordant responses to dynamic testing (intravenous CRH stimulation and HDDST (high-dose dexamethasone suppression test)) or pituitary imaging fails to localize adenoma or reveals pituitary tumor with size $\leq 6 \mathrm{~mm}(12,19,20,21,22)$. As the ACTH secretion is pulsatile, various drugs have been used to stimulate tumoral corticotropes to improve diagnostic accuracy of BIPSS. Ovine/hCRH, desmopressin or combined hCRH and desmopressin have been used during BIPSS in most of the studies $(10,11,12,23,24)$. Vasopressin has been shown to be more potent than CRH in stimulating ACTH secretion in animal studies, though it is equipotent to hCRH in human studies when ACTH is measured from the peripheral vein (13). No study has compared the efficacy and potency of vasopressin and hCRH during BIPSS. In our study, we used hCRH or LVP (5 units or 10 units) for ACTH stimulation during BIPSS and compared their efficacy for localizing and lateralizing the ACTH source (16).

In the present study, we found that sensitivity and PPV of BIPSS for localization of ACTH source was 93.1\% and $100 \%$ at the basal point of time and sensitivity increased to $100 \%$ at $3 \mathrm{~min}$ after stimulation. Further, in most of the studies, peak central-to-peripheral ratio of 3.0 or more usually occurs between 3 and $5 \mathrm{~min}$ post-CRH and desmopressin $(7,26,27,28)$. In a study by Oldfield and coworkers, inferior petrosal sinus: peripheral basal ratio (IPS: $\mathrm{P}$ ) of $\geq 2$ had sensitivity of $95 \%$ and specificity of $100 \%$ for localization, while peak IPS: P ratio of $\geq 3$ after ovine $\mathrm{CRH}$ administration had the sensitivity and specificity of $100 \%$ (7). In one of the largest study by Wind and coworkers, they found that IPSS confirmed a pituitary source of ACTH secretion in 491 patients (98\%) and achieved lateralization in 491 (98\%) patients (9). A study by Machado and coworkers using desmopressin for stimulation during BIPSS, they found that 47 of the 56 patients achieved a central: peripheral ACTH gradient; 40 patients at baseline (IPS:P $\geq 2$ ) and seven patients
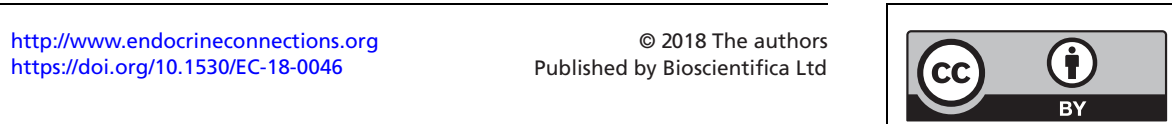

This work is licensed under a Creative Commons Attribution 4.0 International License. 
achieved after desmopressin (IPS:P $\geq 3$ ), achieving a sensitivity of $92.1 \%$ and specificity of $100 \%$ (23). A study by Tsagarakis and coworkers used combined human CRH and desmopressin for stimulation, and they found that sensitivity and specificity of BIPSS for localization was $97.9 \%$ and $100 \%$ respectively (24). In a recent study of 6 patients of CS, BIPSS using LVP as stimulus had sensitivity of $80 \%$ to localize the source of ACTH production. However, small number of patients, low dose of vasopressin $(1 \mathrm{U})$ and absence of active comparator were the limitations of the study (18).

Further, in most of the studies, BIPSS has been done up to $15-20$ min post-stimulation $(9,10,11)$ while in some studies it has been performed up to $60 \mathrm{~min}$ to $120 \mathrm{~min}$ $(23,24,25)$. Using LVP for ACTH stimulation during BIPSS, all patients achieved inferior petrosal sinus: peripheral venous peak ACTH ratio of $\geq 3: 1$ by $2 \mathrm{~min}$, while using hCRH, it was achieved at $3 \mathrm{~min}$ post stimulation in all the patients. Therefore, sampling during BIPSS beyond 5-10 min with either of stimulant is not required.

Maximum stimulated ACTH level of $20,000 \mathrm{pg} / \mathrm{mL}$ and $1687 \mathrm{pg} / \mathrm{mL}$ were achieved with $5 \mathrm{U}$ and $10 \mathrm{U} \mathrm{LVP}$, respectively, while a maximum stimulated ACTH level of $3848 \mathrm{pg} / \mathrm{mL}$ was achieved with $100 \mu \mathrm{g}$ of hCRH. A study by Wind and coworkers has suggested that peak ACTH level, either basal or stimulated $<400 \mathrm{pg} / \mathrm{mL}$ without diagnostic IPS:P ratio is suggestive of false-negative result. One of our patient did not achieve this ACTH value of $400 \mathrm{pg} / \mathrm{mL}$ but had diagnostic IPS:P ratios (9). The stimulated ACTH response depends on multiple factors like potency of stimulus, tumor size, basal ACTH level and magnitude of expression of vasopressin receptors on the tumor tissue.

Use of simultaneous BIPSS is an extremely powerful technique for establishing the central origin of ACTH secretion; however, its diagnostic accuracy for the lateralization of pituitary microadenomas is limited due to the various factors like inter-individual variability in dominant petrosal sinus drainage, anomalous intercavernous sinus venous connections and extension of epicenter of the tumor to the opposite side. Using intersinus ratio of $\geq 1.4: 1$ for lateralization of corticotrope microadenomas, the diagnostic accuracy of inferior petrosal sinus sampling ranges from 50 to $100 \%$, when compared with findings at pituitary surgery as the 'gold standard' $(7,8,9,23,28,29)$.

In the present study, accuracy of BIPSS for lateralizing adenoma was $16 / 22$ patients at the basal point of time. Further, after stimulation with hCRH, 5 U LVP and $10 \mathrm{U}$ LVP, accuracy of lateralization observed was 6/10, 7/9 and $7 / 8$ of patients respectively, denominating the much

$$
\text { http://www.endocrineconnections.org }
$$

higher though not significant correct lateralization after $10 \mathrm{U}$ LVP stimulation as compared to hCRH or $5 \mathrm{U}$ LVP. This can be explained by the higher potency of $10 \mathrm{U}$ LVP for stimulating the ACTH secretion. In a study by Wind and coworkers, they showed that PPV of lateralization was $69 \%$ and left-sided IPSS lateralization with consistent lateralization before and after CRH administration were associated with enhanced accuracy (9). The lateralization depends on multiple factors like potency and specificity of stimulus, tumor size, basal ACTH level and magnitude of expression of vasopressin receptors on tumor tissue.

In our study, concordance rate of CEMRI with BIPSS was 16 out of 24; CEMRI with TSS was 18 out of 24 and BIPSS with TSS was 20 out of 27 patients in lateralizing adenoma, which is comparable to the other studies. In a study by Gillian and coworkers, they found that BIPSS and imaging studies were concordant for $67 \%$ of patients and discordant for 33\% of patients. When results are discordant, BIPSS predicted the side of lesion better than MRI (63\% vs $13 \%$ ), which is in contrast to our study where CEMRI better correlated with TSS when results are discordant between CEMRI and BIPSS (71.4\% vs $28.5 \%$ ) (30). In another study, Colao and coworkers observed that the side of the adenoma as predicted by BIPSS and magnetic resonance imaging was in agreement with surgical evidence in $65 \%$ and $75 \%$ of cases, respectively (12). As in most of the studies, our study also demonstrates that the ability of BIPSS in lateralizing adenoma is limited.

Although BIPSS is a safe procedure in the experienced hands but neurological side effects such as medial medullary syndrome, pontine hemorrhage, subarachnoid hemorrhage, groin hematoma or internal jugular venous (IJV) thrombosis have been described $(9,31,32,33,34,35)$. In our study, one patient developed IJV thrombosis, which is a known complication of BIPSS, rest of the patients had minor side effects that were transient in nature and did not require specific treatment.

The strengths of the study include correlation of BIPSS results with the intra-operative findings, further confirmation by histopathology and an active comparative group. Moreover, LVP is widely available as compared to $\mathrm{CRH}$, thereby enhancing the utility of BIPSS. Small number of patients is the limitation of the study.

In conclusion, this is the first study comparing the use of LVP and hCRH during BIPSS. Both the stimuli confirmed the source of ACTH excess in all the patients, while $10 \mathrm{U}$ LVP could lateralize the pituitary adenoma in higher number of the patients as compare to hCRH or 5 U LVP.

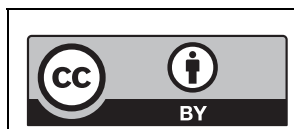

This work is licensed under a Creative Commons Attribution 4.0 International License. 


\section{Declaration of interest}

The authors declare that there is no conflict of interest that could be perceived as prejudicing the impartiality of the research reported.

\section{Funding}

This work did not receive any specific grant from any funding agency in the public, commercial, or not-for-profit sector.

\section{References}

1 Newell-Price J, Trainer P, Besser M \& Grossman A. The diagnosis and differential diagnosis of Cushing's syndrome and pseudo-Cushing's state. Endocrine Review 199819 647-672.

2 Newell-Price J, Bertagna X, Grossman AB \& Nieman LK. Cushing's syndrome. Lancet 2006367 1605-1617.

3 Trainer PJ \& Grossman A. The diagnosis and differential diagnosis of Cushing's syndrome. Clinical Endocrinology 199134 317-330. (https://doi.org/10.1111/j.1365-2265.1991.tb03773.x)

4 Atkinson AB. Management of Cushing's syndrome. Clinical Endocrinology 199134 507-514. (https://doi. org/10.1111/j.1365-2265.1991.tb00332.x)

5 Melby JC. Therapy of Cushing's disease: a consensus for pituitary microsurgery. Annals of Internal Medicine 1989109 445-446. (https:// doi.org/10.7326/0003-4819-109-6-445)

6 Ilias I, Torpy DJ, Pacak K, Mullen N, Wesley RA \& Nieman LK. Cushing's syndrome due to ectopic corticotropin secretion: twenty years' experience at the National Institutes of Health. Journal of Clinical Endocrinology and Metabolism 200590 4955-4962. (https:// doi.org/10.1210/jc.2004-2527)

7 Oldfield EH, Doppman JL, Nieman LK, Chrousos GP, Miller DL, Katz DA, Cutler GB Jr \& Loriaux DL. Petrosal sinus sampling with and without corticotropin-releasing hormone for the differential diagnosis of Cushing's syndrome. New England Journal of Medicine 1991325 897-905. (https://doi.org/10.1056/ NEJM199109263251301)

8 Lopez J, Barcelo B, Lucas T, Salame F, Alameda C, Boronat M, Salto L \& Estrada J. Petrosal sinus sampling for diagnosis of Cushing's disease: evidence of false negative results. Clinical Endocrinology 1996 45 147-156. (https://doi.org/10.1046/j.1365-2265.1996.d01-1550.x)

9 Wind JJ, Lonser RR, Nieman LK, DeVroom HL, Chang R \& Oldfield EH. The lateralization accuracy of inferior petrosal sinus sampling in 501 patients with Cushing's disease. Journal of Clinical Endocrinology and Metabolism 201398 2285-2293. (https://doi. org/10.1210/jc.2012-3943)

10 Wiggam MI, Heaney AP, McIlrath EM, McCance DR, Sheridan B, Hadden DR \& Atkinson AB. Bilateral inferior petrosal sinus sampling in the differential diagnosis of adrenocorticotropin-dependent Cushing's syndrome: comparison with other diagnostic tests. Journal of Clinical Endocrinology and Metabolism 200085 1525-1531.

11 Castinetti F, Morange I, Dufour H, Jaquet P, Conte-Devolx B, Girard N \& Brue T. Desmopressin test during petrosal sinus sampling: a valuable tool to discriminate pituitary or ectopic ACTH-dependent Cushing's syndrome. European Journal of Endocrinology $2007 \mathbf{1 5 7}$ 271-277. (https://doi.org/10.1530/EJE-07-0215)

12 Colao A, Faggiano A, Pivonello R, PecoriGiraldi F, Cavagnini F \& Lombardi G. Inferior petrosal sinus sampling in the differential diagnosis of Cushing's syndrome: results of an Italian Multicenter Study. European Journal of Endocrinology 2001144 499-507. (https:// doi.org/10.1530/eje.0.1440499)

13 Katoh K, Yoshida M, Kobayashi Y, Onodera M, Kogusa K \& Obara Y. Responses induced by arginine-vasopressin injection in the plasma concentrations of adrenocorticotropic hormone, cortisol, growth hormone and metabolites around weaning time in goats. Journal of Endocrinology 2005187 249-256. (https://doi.org/10.1677/ joe.1.06206)

14 Arai K \& Takebe K. Corticotropin response to combined administration of human corticotropin-releasing hormone and small-dose arginine vasopressin in normal subjects. Metabolism 1991 40 1088-1091. (https://doi.org/10.1016/0026-0495(91)90135-J)

15 Salata RA, Jarrett DB, Verbalis JG \& Robinson AG. Vasopressin stimulation of adrenocorticotropin hormone (ACTH) in humans. Journal of Clinical Investigation 198881 766-774. (https://doi. org/10.1172/JCI113382)

16 Gaillard RC, Riondel AM, Ling N \& Muller AF. Corticotropin releasing factor activity of CRF 41 in normal man is potentiated by angiotensin II and vasopressin but not by desmopressin. Life Sciences 198843 1935-1944. (https://doi.org/10.1016/S0024-3205(88)80012-2)

17 Dahia PL, Ahmed-Shuaib A, Jacobs RA, Chew SL, Honegger J, Fahlbusch R, Besser GM \& Grossman AB. Vasopressin receptor expression and mutation analysis in corticotropin-secreting tumors. Journal of Clinical Endocrinology and Metabolism 199681 1768-1771.

18 Kotwal N, Kumar Y, Upreti V, Singh A \& Garg MK. Bilateral inferior petrosal sinus sampling using vasopressin. Indian Journal of Endocrinology and Metabolism 201620 399-403. (https://doi. org/10.4103/2230-8210.179995)

19 Booth GL, Redelmeier DA, Grosman H, Kovacs K, Smyth HS \& Ezzat S. Improved diagnostic accuracy of inferior petrosal sinus sampling over imaging for localizing pituitary pathology in patients with Cushing's disease. Journal of Clinical Endocrinology and Metabolism 199883 2291-2295.

20 Boscaro M, Rampazzo A, Paoletta A, Roseano P, Pagotto U, Fallo F \& Sonino N. Selective venous sampling in the differential diagnosis of ACTH dependent Cushing's syndrome. Neuroendocrinology $1992 \mathbf{5 5}$ 264-268. (https://doi.org/10.1159/000126124)

21 Findling JW \& Raff H. Cushing's syndrome: important issues in diagnosis and management. Journal of Clinical Endocrinology and Metabolism 200691 3746-3753. (https://doi.org/10.1210/jc.20060997)

22 Arnaldi G, Angeli A, Atkinson AB, Bertagna X, Cavagnini F, Chrousos G, Fava GA, Findling JW, Gaillard RC, Grossman AB, et al. Diagnosis and complications of Cushing's syndrome: A consensus statement. Journal of Clinical Endocrinology and Metabolism $2003 \mathbf{8 8}$ 5593-5602. (https://doi.org/10.1210/jc.2003-030871)

23 Machado MC, de Sa SV, Domenice S, Fragoso MC, Puglia P Jr, Pereira MA, de Mendonça BB \& Salgado LR. The role of desmopressin in bilateral and simultaneous inferior petrosal sinus sampling for differential diagnosis of ACTH-dependent Cushing's syndrome. Clinical Endocrinology 200766 136-142.

24 Tsagarakis S, Vassiliadi D, Kaskarelis IS, Komninos J, Souvatzoglou E $\&$ Thalassinos N. The application of the combined corticotropinreleasing hormone plus desmopressin stimulation during petrosal sinus sampling is both sensitive and specific in differentiating patients with Cushing's disease from patients with the occult ectopic adrenocorticotropin syndrome. Journal of Clinical Endocrinology and Metabolism 200792 2080-2086. (https://doi.org/10.1210/jc.20062691)

25 Landolt AM, Schubiger O, Maurer R \& Girard J. The value of inferior petrosal sinus sampling in diagnosis and treatment of Cushing's disease. Clinical Endocrinology 199440 485-492. (https://doi. org/10.1111/j.1365-2265.1994.tb02487.x)

26 Colao A, Merola B, Tripodi FS, Di Sarno A, Esposito V, Marzullo P, La Tessa G, Spaziante R \& Lombardi G. Simultaneous and bilateral inferior petrosal sinus sampling for the diagnosis of Cushing's syndrome: comparison of multihormonal assay, baseline multiple sampling and ACTH-releasing hormone test. Hormone Research 1993 40 209-216. (https://doi.org/10.1159/000183797)

27 Padayatty SJ, Orme SM, Nelson M, Lamb JT \& Belchetz PE. Bilateral sequential inferior petrosal sinus sampling with corticotrophinreleasing hormone stimulation in the diagnosis of Cushing's disease. http://www.endocrineconnections.org https://doi.org/10.1530/EC-18-0046
() 2018 The authors Published by Bioscientifica Ltd
This work is licensed under a Creative Commons Attribution 4.0 International License. 
European Journal of Endocrinology 1998139 161-166. (https://doi. org/10.1530/eje.0.1390161)

28 McCance DR, McIlrath E, McNeill A, Gordon DS, Hadden DR, Kennedy L, Sheridan B \& Atkinson AB. Bilateral inferior petrosal sinus sampling as a routine procedure in ACTH-dependent Cushing's syndrome. Clinical Endocrinology 198930 157-166. (https://doi org/10.1111/j.1365-2265.1989.tb03737.x)

29 Landolt AM, Valavanis A, Girard J \& Eberle AN. Corticotrophinreleasing factor-test used with bilateral, simultaneous inferior petrosal sinus blood-sampling for the diagnosis of pituitarydependent.Cushing's disease. Clinical Endocrinology 198625 687-696. (https://doi.org/10.1111/j.1365-2265.1986.tb03624.x)

30 Gillian LB, Donald AR, Harvey G, Kalman K, Harley SS \& Shereen E. Improved diagnostic accuracy of inferior petrosal sinus sampling over imaging for localizing pituitary pathology in patients with Cushing's disease. Journal of Clinical Endocrinology and Metabolism 199883 2291-2295.

31 Gandhi CD, Meyer SA, Patel AB, Johnson DM \& Post KD. Neurologic complications of inferior petrosal sinus sampling. American Journal of Neuroradiology 200829 760-765. (https://doi.org/10.3174/ajnr. A0930)

32 Bonelli FS, Huston J 3rd, Meyer FB \& Carpenter PC. Venous subarachnoid hemorrhage after inferior petrosal sinus sampling for adrenocorticotropic hormone. American Journal of Neuroradiology 199920 306-307.

33 Miller DJ \& Doppman JL. Petrosal sinus sampling: technique and rationale. Radiology $1991 \mathbf{1 7 8} 37-47$. (https://doi.org/10.1148/ radiology.178.1.1845785)

34 Obuobie K, Davies JS, Ogunko A \& Scanlon MF. Venous thromboembolism following inferior petrosal sinus sampling in Cushing's disease. Journal of Endocrinological Investigation 200023 542-544. (https://doi.org/10.1007/BF03343772)

35 Potts MB, Shah JK, Molinaro AM, Blevins LS, Tyrrell JB, Kunwar S, Dowd CF, Hetts SW \& Aghi MK. Cavernous and inferior petrosal sinus sampling and dynamic magnetic resonance imaging in the preoperative evaluation of Cushing's disease. Journal of Neurooncology 2014116 593-600. (https://doi.org/10.1007/s11060013-1342-9)

Received in final form 7 February 2018

Accepted 12 February 2018

Accepted Preprint published online 12 February 2018 http://www.endocrineconnections.org https://doi.org/10.1530/EC-18-0046 (c) 2018 The authors Published by Bioscientifica Ltd

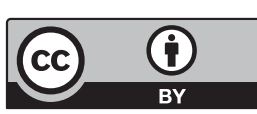

This work is licensed under a Creative Commons Attribution 4.0 International License. 